\title{
XPS study of 5-chloro-1,2,3-benzotriazole adsorption on nickel surface $^{1}$
}

\section{A. Arkhipushkin, L. I. Yesina, Yu. Ya. Andreev, L. P. Kazansky* and Yu. I. Kuznetsov}

A. N. Frumkin Institute of Physical Chemistry and Electrochemistry, Russian Academy of Sciences, Leninskii pr. 31, Moscow, 119071 Russian Federation

*E-mail:leoka@ipc.rssi.ru

\begin{abstract}
Surface layers formed by adsorption of 5-chloro-1,2,3-benzotriazole (5-chloroBTA) on nickel and influence of $\mathrm{pH}$ of borate buffer solution and electrode potential on formation multicomponent oxidized films on nickel were studied by XPS. It was found that at concentration of $10^{-4} \mathrm{~mol} / 1$ in neutral borate solutions a $0.7 \mathrm{~nm}$ monomolecular layer of 5chloroBTA is formed. Using peak intensity angular dependence of XPS spectra the orientation of 5-chloroBTA close to vertical on nickel hydroxide formed on the nickel surface was shown. 5-ChloroBTA forms a chemical bond by lone pair of nitrogen and surface nickel cations.
\end{abstract}

Keywords: nickel, 5-chloroBTA, inhibitor, azoles, XPS.

Received: October 13, 2012.

doi: $10.17675 / 2305-6894-2012-1-2-107-116$

\section{Introduction}

The electrochemical and adsorption behavior of nickel in neutral $(\mathrm{pH}$ 7.4) and alkaline (pH 9.1) solutions with 1,2,3-benzotriazole (BTA) and it's chlorine derivative 5-chlorobenzotriazole (5-chloroBTA) has been examined in [1]. Surface nickel oxides formation was studied in situ by ellipsometry. Adsorption isotherms of BTA and 5-chloroBTA on nickel at the electrode potentials $E=-0.65 \mathrm{~V}$ and $0.2 \mathrm{~V}$ were obtained. The anodic polarization curves show a possible stabilization of the passive state in borate-chloride solutions with triazoles added. BTA is proved to be less efficient than 5-chloroBTA, although the difference between inhibitors is less than in case of copper and mild steel. That research leaves an open question about the nature of the adsorption bonding of triazoles and demands additional investigations.

There are several publications dealing with BTA interaction with the Ni surface. The Raman spectra of BTA surface layers depending on the applied potential were obtained and it was preliminary stated (because of low intensity spectra) that a complex of neutral

\footnotetext{
${ }^{1}$ This study is supported by program no. 8 of fundamental research released by Department of Chemistry and Material Science (New ways to increase corrosion and radiation stability of materials, radioecological safety) of the Russian Academy of sciences.
} 
molecule of BTA and nickel forms [2]. Notoya et al. [3] using time-of-flight massspectrometry have shown that exposing the nickel electrode in solution containing BTA results in the formation of a complex with variable composition $\left(\mathrm{Ni}_{m}(\mathrm{BTA})_{m+1}\right)_{n}$ where $m$ and $n$ can be equal to 1 and 2. In other publications the influence of BTA on copper-nickel alloys corrosion was investigated [4-6].

In the present paper the results of the X-ray photoelectron spectroscopic (XPS) studies of the surface layers formed on nickel exposed in pure borate solutions and with 5chloroBTA added are given.

\section{Experimental}

Specimens of polycrystalline nickel (99.99\%) in the form of disks of $10 \mathrm{~mm}$ diameter, polished with sandpaper (1000) and diamond powder to mirror finish, and rinsed in ultrasonic bath by doubly distilled water for 5 minutes. Afterwards specimens were cathodically activated in a three-electrode cell to remove an air formed oxide, and then the anodic potential corresponding to the oxide layer formation was stepwise applied and kept for $60 \mathrm{~min}$. Required amount of 5-chloroBTA was added in the concentration optimally corresponding formation of a monomolecular film, which is defined from ellipsometric data [11]. To remove physically adsorbed molecules of 5-chloroBTA the specimens were sonicated in bidistillate within $10 \mathrm{~min}$, and then immediately transferred to the spectrometer chamber. XP spectra of the surface layers formed were registered by means of the special analyzer chamber CLAM100 set on Auger microscope HB100 (Vacuum Generators, GB). Pressure in the analytical chamber was below $10^{-8}$ Torr. The Al anode $(1486.6 \mathrm{eV})$ is used as the X-ray source $(200 \mathrm{~W})$. Analyzer pass energy is set at $50 \mathrm{eV}$ and sometimes at $20 \mathrm{eV}$ to increase resolution. The spectrometer was calibrated by XPS peaks of metals: $\mathrm{Au} 4 \mathrm{f}_{7 / 2}\left(E_{\mathrm{b}}=84.0 \mathrm{eV}\right), \mathrm{Cu} 2 \mathrm{p}_{3 / 2}\left(E_{\mathrm{b}}=932.5 \mathrm{eV}\right)$, measured after cleaning the surfaces of metals by argon ions. Position of XPS peaks of the corresponding elements is referred to the $\mathrm{C} 1 \mathrm{~s}$ peak of carbonaceous contamination, whose energy is taken equal to $285.0 \mathrm{eV}$. The peak positions were reproduced better than $\pm 0.15 \mathrm{eV}$.

For the further spectrum processing the individual spectra of $\mathrm{NiO}$ and $\mathrm{Ni}(\mathrm{OH})_{2}$ powders and metallic Ni cleaned by argon ions sputtering have been registered. Deconvolution of spectrums into individual Gauss - Lorenz curves was carried out after the Shirley background subtraction [7]. To calculate the thickness of the formed layers for assumed model of the surface film a program MultiQuant developed by Mohai [8] is used, in which the integrated intensity of all elements forming a surface film were taken into account. This software is based on fitting the experimental and calculated integral peak intensities. The formed film was divided in some parallel layers (contamination, inhibitor layer, oxide and metal). It was thus supposed that the corresponding atoms are uniformly distributed in their layers. The cross sections of the electronic shells $\sigma$, calculated by Scofield [9] are generally used. Mean escape depths $\lambda$, are calculated according to Cumpson and Seah [10] by program MultiQuant, which has also been used for simulating 
the intensities of the peaks taking into account the thickness of the layers estimated from the experimental values.

\section{Results and discussion}

As the in situ ellipsometric study of 5-chloroBTA adsorption on the nickel electrode has shown that the concentration increase results in inhibitor layer growth and at $10^{-3} \mathrm{~mol} / 1$ it stops growing [1]. The $\mathrm{pH}$ of solution used is found to have no effect on the layer thickness. To assess layer thickness XPS method was applied. In some publications [1119] XPS was used to examine the surface layer composition on nickel and its alloys in various media, and it is accepted that at low anodic potentials the Ni surface is covered with only $\mathrm{NiO}$ and $\mathrm{Ni}(\mathrm{OH})_{2}$. However $\mathrm{Ni} 2 \mathrm{p}$ spectra are complicated by different multiplets, satellite peaks, plasma losses and oxidation states, some difficulties arise in their interpretation $[20,21]$.

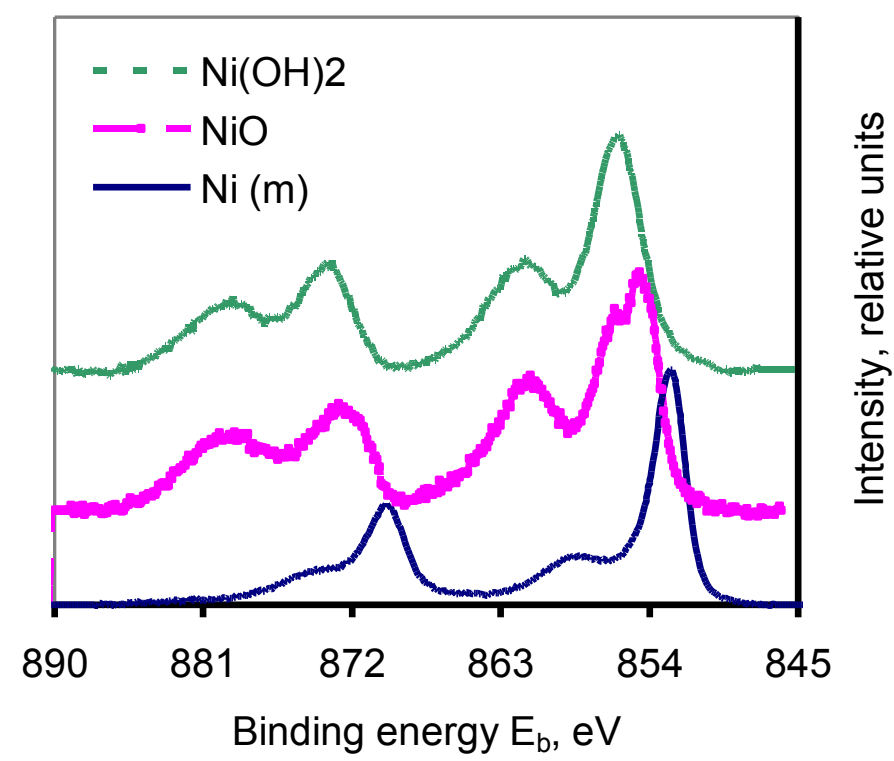

Fig. 1. XP spectra $\mathrm{Ni} 2 \mathrm{p}$ electrons of $\mathrm{Ni}, \mathrm{NiO}$, and $\mathrm{Ni}(\mathrm{OH})_{2}$

To identify the surface layer composition on nickel, spectra of $\mathrm{NiO}, \mathrm{Ni}(\mathrm{OH})_{2}$ and pure $\mathrm{Ni}$ were studied. $\mathrm{Ni}_{2} \mathrm{p}_{3 / 2}$ peak maximums of individual compounds (Fig. 1) fairly correspond to those given in other publications [20-22]. Table 1 presents the measured XPS peak positions of corresponding elements.

Specimen exposed at $0.2 \mathrm{~V}$ in pure borate buffer solution $(\mathrm{pH} 7.4)$ for $1 \mathrm{~h}$ gives a complex XP spectrum of the Ni2p electrons (Fig. 2a). Presence of the metallic Ni2p doublet indicates thin oxidized film formation. The similar spectrum appears if specimen was exposed at $\mathrm{pH} 9.1$.

Because potentials of film growth are fairly low to form trivalent oxides, they were not taken into account when the experimental spectra have been deconvoluted and fitted. 
The XPS shape of the Ni2p electrons obtained could be fitted only if nickel states as $\mathrm{Ni}^{0}$, $\mathrm{NiO}$ and $\mathrm{Ni}(\mathrm{OH})_{2}$ are taken into account (Fig. 2). Using least-square-error proportion between peak intensities of oxide and hydroxide is chosen in such a way to satisfy the lowest deviation of the simulated spectrum from the experimental one. The presence of $\mathrm{NiO}, \mathrm{Ni}(\mathrm{OH})_{2}$ and adsorbed water is approved by the $\mathrm{O} 1 \mathrm{~s}$ spectrum that can be divided into three peaks (Fig. 3).

Table 1. Spectra line positions of atoms of examined substances.

\begin{tabular}{ccc}
\hline Spectrum line & Substance & $\mathbf{E}_{\mathbf{b}}, \mathbf{e V}$ \\
\hline \multirow{2}{*}{$\mathrm{O} 1 \mathrm{~s}$} & $\mathrm{NiO}$ & 529.5 \\
\cline { 2 - 3 } & $\mathrm{Ni}(\mathrm{OH})_{2}$ & 531.2 \\
\cline { 2 - 3 } & $\mathrm{H}_{2} \mathrm{O}$ & 532.7 \\
\cline { 2 - 3 } $\mathrm{Ni2} \mathrm{p}_{3 / 2}$ & $\mathrm{Ni}$ & 852.7 \\
\cline { 2 - 3 } & $\mathrm{NiO}$ & 854.4 \\
\hline $\mathrm{N} 1 \mathrm{~s}$ & $\mathrm{Ni}(\mathrm{OH})_{2}$ & 855.9 \\
\hline $\mathrm{C} 12 \mathrm{p}$ & $-\mathrm{N}-$ & 400.8 \\
\hline
\end{tabular}
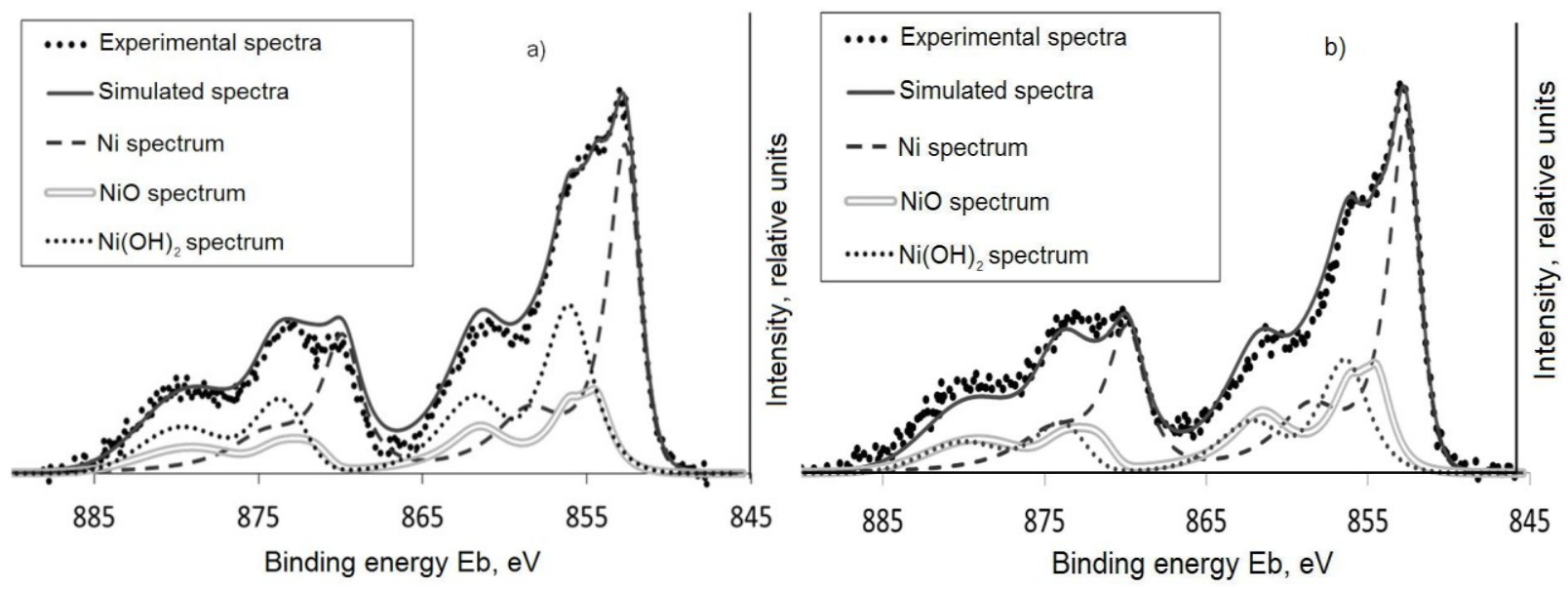

Fig. 2. XP spectra of Ni specimens at $E=+0.2 \mathrm{~V}, \mathrm{pH}=7.4$ in borate buffer $(a)$ and with 5chloroBTA added $(b)$.

Spectra integral intensities were used for calculation of the layers thickness formed on $\mathrm{Ni}$ surface (Table 2). It was assumed that $\mathrm{NiO}$ layer is located between metallic $\mathrm{Ni}$ and $\mathrm{Ni}(\mathrm{OH})_{2}$.

Total oxide layer thickness for specimens exposed at $\mathrm{pH} 7.4$ and $\mathrm{pH} 9.1$ is $\sim 1 \mathrm{~nm}$ (Table 2, No. 1, 4, 8, 10). Specimen exposition in 5-chloroBTA solution causes the N1s (Fig. $3 b$ ) and $\mathrm{Cl} 2$ p peaks to appear. Table 2 presents thicknesses calculated for some 
experiments with different conditions. When 5-chloroBTA adsorbs, the N1s peak position moves from $401.0 \mathrm{eV}$ for 5-chloroBTA (crystal powder) to $400.4 \mathrm{eV}$ (Fig. 3b). The observed chemical shift and peak FWHM reduction from 2.91 to $2.42 \mathrm{eV}$ demonstrate the
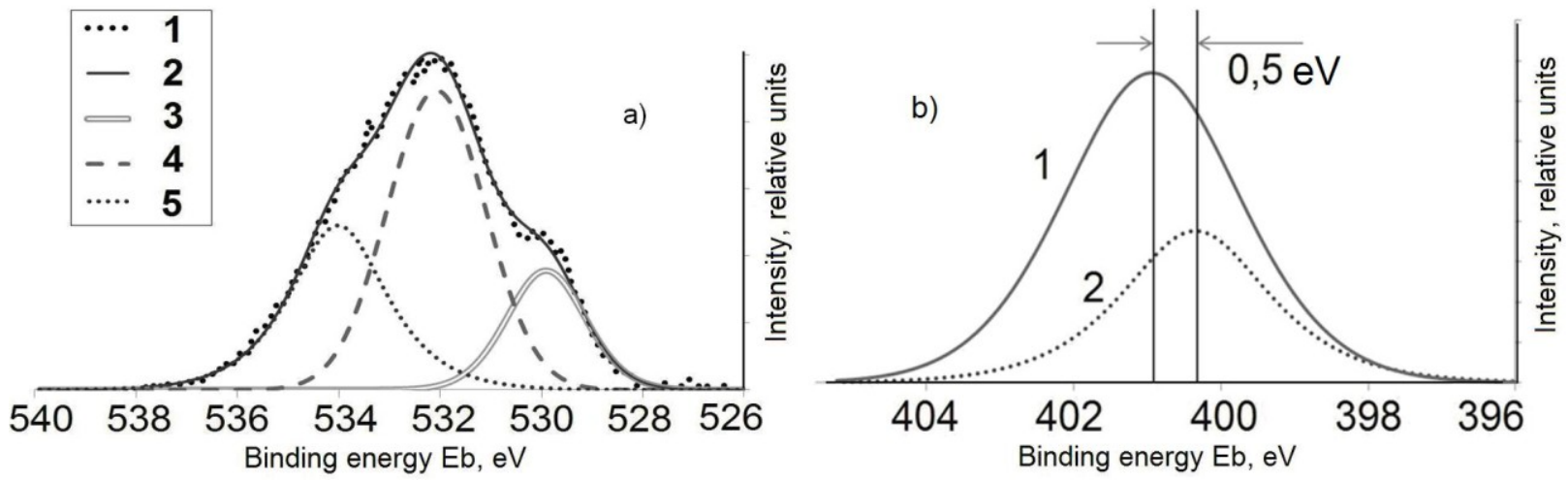

Fig. 3. XP spectra: $a$ ) O1s electrons on Ni surface, exposed in borate buffer. 1 - experimental spectrum, 2 - simulated spectrum, $\left.3-\mathrm{NiO}, 4-\mathrm{Ni}(\mathrm{OH})_{2}, 5-\mathrm{H}_{2} \mathrm{O} ; b\right) \mathrm{N} 1$ s electrons of 5chloroBTA powder (1) and adsorbed (2).

electronic density averaging around nitrogen atoms because of deprotonation and chemical bond formation between $\mathrm{N}$ lone pair and nickel cations. Cl2p peak position doesn't change when 5-chloroBTA adsorbs. In this case the Ni2p electrons show lower presence of oxide components (Fig. 2b) and consequently the lower oxide layer thickness.

Table 2. Treatment conditions and layer thickness formed on Ni surface

No.

Treatment conditions

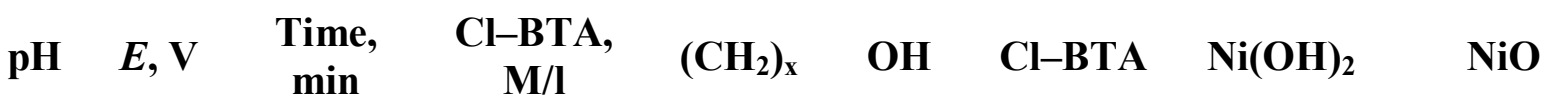

\begin{tabular}{cccccccccc}
\hline 1 & 9.1 & +0.2 & - & - & 1.50 & 0.61 & - & 0.70 & 0.24 \\
2 & 9.1 & +0.2 & 75 & $10^{-6}$ & 1.79 & 0.33 & 0.43 & 1.00 & 0.23 \\
3 & 9.1 & +0.2 & 135 & $10^{-6}$ & 1.50 & 1.01 & 0.33 & 0.61 & 0.25 \\
4 & 7.4 & +0.2 & - & - & 1.74 & 0.78 & - & 0.78 & 0.32 \\
5 & 7.4 & +0.2 & 75 & $10^{-6}$ & 3.09 & 1.31 & 0.26 & 0.47 & 0.21 \\
6 & 7.4 & +0.2 & 135 & $10^{-3}$ & 1.42 & 0.57 & 1.08 & 0.46 & 0.21 \\
7 & 7.4 & +0.2 & 180 & $10^{-4}$ & 1.79 & 0.76 & 0.67 & 0.61 & 0.26 \\
8 & 7.4 & -0.1 & - & - & 1.99 & 0.80 & - & 0.60 & 0.15 \\
9 & 7.4 & -0.1 & 180 & $10^{-4}$ & 1.81 & 0.69 & 0.82 & 0.58 & 0.35 \\
10 & 7.4 & - & - & - & 3.22 & 0.39 & - & 0.84 & 0.38 \\
11 & 7.4 & - & 7200 & $10^{-2}$ & 2.90 & 0.57 & 0.83 & 0.81 & 0.27 \\
\hline
\end{tabular}


For layer thickness calculation, density of surface compounds is required. For closepacked molecules of 5-chloroBTA, its density calculated from Van der Waals radii and molecular weight is $1.49 \mathrm{~g} / \mathrm{cm}^{3}$. However, when adsorbed, it can change because it may be determined by presence of free cations that coordinate organic molecule. It will be shown later, its density can be reduced under $1.17 \mathrm{~g} / \mathrm{cm}^{3}$. That's why a mean value of $1.30 \mathrm{~g} / \mathrm{cm}^{3}$ was taken. The densities of $\mathrm{NiO}$ and $\mathrm{Ni}(\mathrm{OH})_{2}$ were taken as 6.65 and $3.65 \mathrm{~g} / \mathrm{cm}^{3}$, respectively.

From the data acquired we may conclude that at low concentration $\left(10^{-6} \mathrm{~mol} / \mathrm{l}\right) \mathrm{pH}$ value and time (up to $2 \mathrm{~h}$ ) doesn't affect the 5-chloroBTA layer thickness $(0.34 \pm 0.07 \mathrm{~nm})$. At $10^{-4} \mathrm{~mol} / 1$ film growth stops at $0.86 \pm 0.23 \mathrm{~nm}$. Value dispersion is explained by adsorption on rough surface and some molecules are situated in grooves. Rough surface modeling by pyramids [23] leads to obvious thickness decrease by $\sim 0.2 \mathrm{~nm}$. Whereas nitrogen to chlorine distance is $0.57 \mathrm{~nm}$, this value (taking into account Van der Waals radii) is close to calculated thickness of 5-chloroBTA adsorbed on the oxidized Ni surface.

It is worth noting that when 5-chloroBTA is adsorbed, atomic ratio $\mathrm{N}: \mathrm{Cl}$ is lower than 3, shows a certain inhomogeneity of atom distribution caused by orientation of molecules. The same is observed when 5-chloroBTA adsorbs to nickel oxidized in water.

The second batch of specimens was not processed electrochemically. Polished and washed in ultrasonic bath they were put into hot distilled water and exposed for $1 \mathrm{~h}$ at $70^{\circ} \mathrm{C}$, later in $12.5 \mathrm{mM} / 1$ 5-chloroBTA solution for $12 \mathrm{~h}$. It should be noted that before inhibitor deposition, the nickel specimen oxidized layer had the same composition as the one, prepared electrochemically (Table 2, exp. 10). After second ultrasonic washing, XP spectra were registered at two angles $\theta\left(15^{\circ}\right.$ and $\left.45^{\circ}\right)$ of the electronis emission [24]. $\theta$ is angle between trajectory of emission and normal to specimen surface. If an angle increased, metallic component of $\mathrm{Ni} 2 \mathrm{p}$ doublet spectrum decreases. At the same time $\mathrm{N}: \mathrm{Cl}$ ratio decreases from 2.21 to 1.88 showing inhomogeneous distribution of these atoms in the surface layers.

The approach from $[25,26]$ was used to calculate relative depth distribution of atoms. Logarithm of peak intensity ratio is measured at high $\left(50^{\circ}\right)$ and low $\left(15^{\circ}\right)$ electron emission angles. It is known that XPS-peak intensity of atoms $I_{0}$ under layer of thickness $d$ is determined according to equation [27]:

$$
I=I_{0} \exp (-d / \lambda \cos \theta),
$$

where $\theta$ - electron emission angle, $\lambda$ - electron free path in screening layer for given orbital. Having measured peak intensity at two angles $\theta_{1}$ and $\theta_{2}$, we can find logarithm of intensity ratio (LIR):

$$
\begin{gathered}
I_{1} / I_{2}=\exp \left(-d / \lambda \cos \theta_{1}\right) / \exp \left(-d / \lambda \cos \theta_{2}\right) \\
\ln \left(I_{1} / I_{2}\right)=\left(-d / \lambda \cos \theta_{1}\right)-\left(-d / \lambda \cos \theta_{2}\right) \\
-\ln \left(I_{1} / I_{2}\right)=\left(\mathrm{d} / \lambda \cos \theta_{1}\right)-\left(\mathrm{d} / \lambda \cos \theta_{2}\right)
\end{gathered}
$$




$$
-\ln \left(I_{1} / I_{2}\right)=\mathrm{d}\left[\left(1 / \lambda \cos \theta_{1}\right)-\left(1 / \lambda \cos \theta_{2}\right)\right]
$$

As $\left[\left(1 / \lambda \cos \theta_{1}\right)-\left(1 / \lambda \cos \theta_{2}\right)\right]$ is formally constant, LIR gives information about relative in-depth distribution of atoms. The less is logarithm value, the deeper element is allocated. However in this approach there are some restrictions. Firstly, layered-like structure is assumed, secondly, it is desirable to compare atoms with similar kinetic energies $E_{\mathrm{k}}$, because it affects $\lambda$, the electron mean path. No doubt that logarithm value will be averaged for the same atoms in several layers.

To neutralize the effect of carbon surface contaminations the experimental intensity values were normalized by carbon peak intensity for each angle, and later their ratio was calculated.

In Fig. 4 the intensity ratio logarithm $\ln \left(I_{50} / I_{15}\right)$ is shown for atoms in layer formed by 5-chloroBTA in borate solution on nickel surface. In this diagram all the points are situated diagonally (for illustration purposes), and it could be seen how atoms are arranged in the overlayer. An obvious surpassing of $\ln \left(I_{50} / I_{15}\right)$ for chlorine comparing with nitrogen indicates deeper location of $\mathrm{N}$ in the adsorbed layer. Nevertheless it should be noted that $\lambda$ $(3.86 \mathrm{~nm})$ for chlorine is greater than for nitrogen $(3.36 \mathrm{~nm})$ and angle increase will a priori give greater value of $\ln \left(I_{50} / I_{15}\right)$ for chlorine even for homogeneously distributed atoms. Thereby the MultiQuant program was applied to simulate peak intensity for two angles, based on model with thickness of layers found from experimental intensities. Calculated intensity ratio logarithms are also plotted in the diagram (Fig. 4).

Because of averaging the experimental thickness values for two angles used in calculation some discrepancies in experimental and simulated in-depth distributions are observed. As expected, $\ln \left(I_{50} / I_{15}\right)$ for chlorine is greater than for nitrogen nevertheless the value difference (0.07) is much larger for experiment $(0.16 \pm 0.02)$ (Fig. 4). It clearly shows that chlorine atoms are situated above the nitrogen ones that corresponds to almost vertical orientation of 5-chloroBTA molecules on the oxidized Ni surface.

As $\alpha-\mathrm{Ni}(\mathrm{OH})_{2}$ is unstable we suppose the topmost layer is a stable $\beta-\mathrm{Ni}(\mathrm{OH})_{2}$ with brucite (native magnesia) structure [28], it is possible to assume 5-chloroBTA allocation using crystal's structure parameters on $\beta-\mathrm{Ni}(\mathrm{OH})_{2}(001)$ (Fig. 5).

According to crystallographic parameters [29] BTA molecule volume is $145 \AA^{3}$ and its density is $1.33 \mathrm{~g} / \mathrm{cm}^{3}$. Chlorine atom increases 5-chloroBTA volume and density up to $1.49 \mathrm{~g} / \mathrm{cm}^{3}$. However, this density is for close-packed molecules, and could be inaccessible on surface disposition only at free vacant nickel cation. For instance, face area of $\mathrm{Ni}(\mathrm{OH})_{2}$ (100) is $13.81 \AA^{2}$, that is half of area required for vertical placement of one anion of 5chloroBTA $\left(\sim 25 \AA^{2}\right)$, (projection on area perpendicular to pseudo $C_{2}$ axis of anion). For this reason, it is possible to allocate only one 5-chloroBTA molecule on two neighbor faces. When monolayer of vertical-positioned molecules is formed on this face, its density may attain $1.39 \mathrm{~g} / \mathrm{cm}^{3}$. However, on other faces the 5-chloroBTA density is lower as one molecule takes larger area because of the lack of nickel cations on the surface that could coordinate 5-chloroBTA. Considering that nickel specimen is polycrystalline, the layer 
density will be averaged and for all calculations density variation from 1.2 up to $1.39 \mathrm{~g} / \mathrm{cm}^{3}$ will reduce the calculated 5-chloroBTA layer thickness for $0.2 \mathrm{~nm}$. This value almost matches acceptable error for layer thickness calculation. It should be pointed out that 5chloroBTA adsorption on the oxidized surface of iron, copper and zinc also results in monolayer formation not exceeding $0.7 \mathrm{~nm}$ [30]. While adsorption on $\mathrm{Ni}$ and Fe terminates with monolayer formation, on $\mathrm{Cu}$ and $\mathrm{Zn}$ a surface layer grows up to several nanometers and consists of apparently insoluble polymeric complexes.

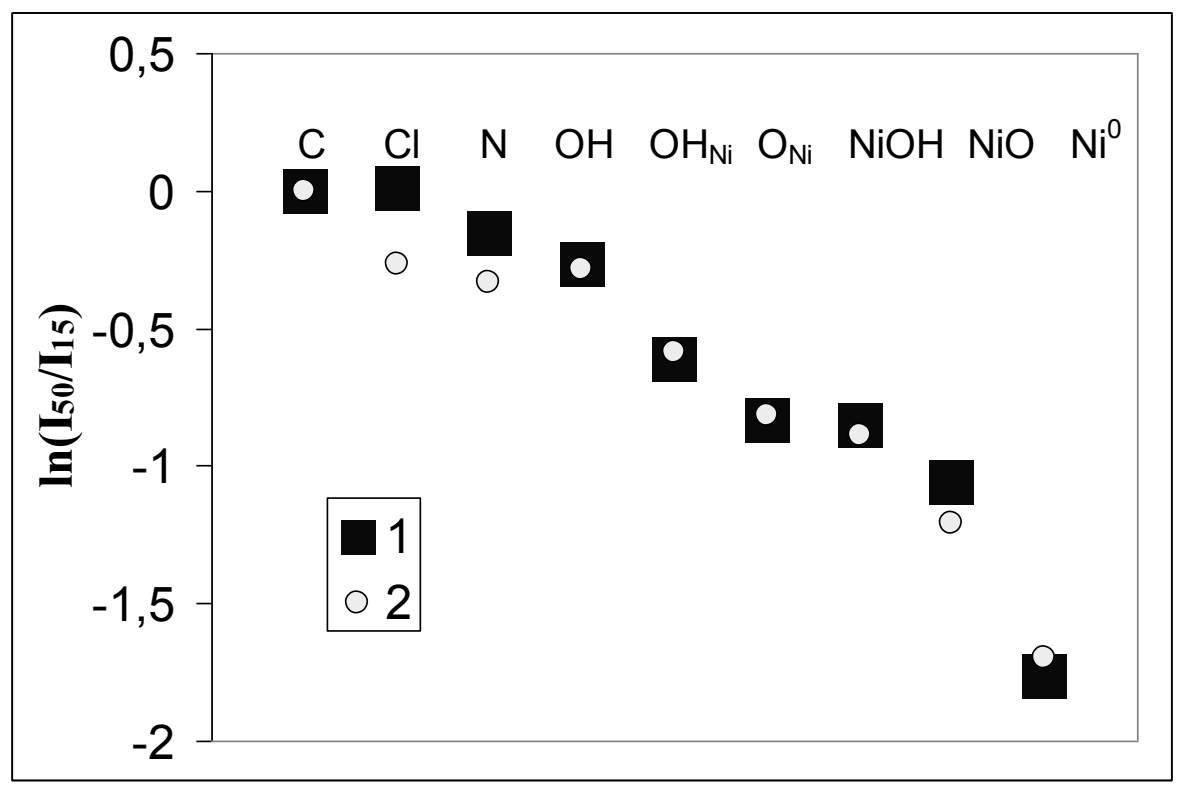

Fig. 4. $\ln \left(I_{1} / I_{2}\right)$ variation plot and relative in-depth atomic distribution. 1 - experiment, 2 - simulation.
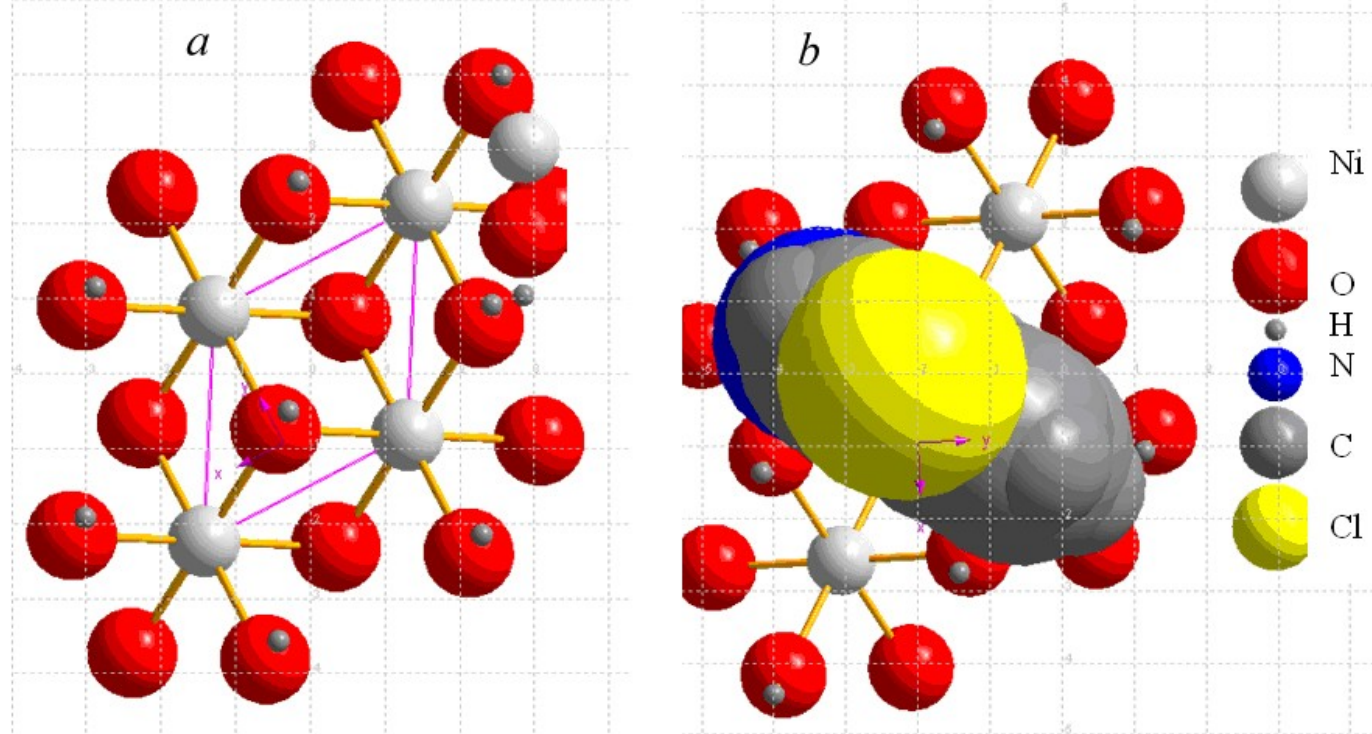

Fig. 5. Atoms order in $\beta-\mathrm{Ni}(\mathrm{OH})_{2}(001$-face) (a) and possible 5-chloroBTA anion allocation on this face $(b)$. 


\section{Conclusions}

1. Nickel exposition in borate buffer solution at potential $+0.2 \mathrm{~V}$ causes thin $(1 \mathrm{~nm})$ oxide layer formation, composed of $\mathrm{NiO}$ and $\mathrm{Ni}(\mathrm{OH})_{2}$.

2. When 5-chloroBTA is adsorbed on oxidized nickel surface, monomolecular layer forms, thereby oxide layer thickness decreases. 5-chloroBTA layer thickness is $0.8 \pm 0.2 \mathrm{~nm}$ and almost doesn't depend on $\mathrm{pH}$ and 5-chloroBTA concentration.

3. Angular dependence of XP spectra evidences vertical orientation of 5-chloroBTA anions fixed on surface by lone pair of nitrogen, and chlorine atoms form a virtual topmost layer.

\section{References}

1. N. P. Andreeva, Yu. Ya. Andreev, L. I. Yesina and Yu. I. Kuznetsov, Korroz.: Mater. Zashch., in press (in Russian).

2. P. G. Cao, J. L. Yao, J. W. Zheng, R. A. Gu and Z. Q. Tian, Langmuir, 2002, 18, 100.

3. T. Notoya, M. Satake, T. Ohtsuka, H. Yahiro, M. Sato, T. Tumauchi and D. P. Schweinsberg, J. Corros. Sci. Eng., 2003, 6, preprint 31 (Conference "Corrosion Science in the 21 th century, UMIST, July, 2003).

4. N. K. Allam, H. S. Hegazy and E. A. Ashour, Int. J. Electrochem. Sci., 2007, 2, 549.

5. A. A. Khadom, A. S. Yaro, A. A. H. Kadhum, J. Chil. Chem. Soc., 2010, 55, 150.

6. J. Maciel, R. F. V. Jaimes, P. Corio, J. C. Rubim, P. L. Volpe, A. A. Neto and S. M. L. Agostinho, Corros. Sci., 2008, 50, 879.

7. D. A. Shirley, Phys. Rev. B., 1972, 5, 4709.

8. M. Mohai, Surf. Interface Anal., 2004, 36, 828.

9. H. Scofield, J. Electron Spectrosc. Relat. Phenom., 1976, 8, 129.

10. P. J. Cumpson and M. P. Seah, Surf. Interface Anal., 1997, 25, 430.

11. M. C. Oliveira and A. M. Botelho do Rego, J. Alloys and Comp., 2006, 425, 64.

12. A. Kawashima, K. Asami and K. Hashimoto, Corros. Sci., 1985, 25, 103.

13. H.-W. Hoppe and H.-H. Strehblow, Corros. Sci., 1990, 31, 167.

14. H.-W. Hoppe and H.-H. Strehblow, Surf. Interface Anal., 1989, 14, 121.

15. S.-J. Panga, C.-H. Sheka, T. Zhang, K. Asami and A. Inoue, Corros. Sci., 2006, 48, 625.

16. A. Macheta, A. Galtayriesa, S. Zanna, L. Kleina, V. Maurice, P. Jolivet, M. Foucault, P. Combrade, P. Scott and P. Marcus, Electrochim. Acta, 2004, 49, 3957.

17. J. Kang, Y. Yang and H. Shao, Corros. Sci., 2009, 51, 1907.

18. M. Arfelli, G. M. Ingo, G. Mattogno and A. M. Beccaria, Surf. Interface Anal., 1990, 16, 299.

19. L. Zhang and D. D. Macdonald, Electrochim. Acta, 1998, 43, 2661.

20. M. C. Biesinger, B. P. Payne, L. W. M. Lau, A. Gerson and R. St. C. Smart, Surf. Interface Anal., 2009, 41, 324. 
21. B. P. Payne, A. P. Grosvenor, M. C. Biesinger, B. A. Kobe and N. S. McIntyre, Surf. Interface Anal., 2007, 39, 582.

22. L. J. Matienzo, L. I. Yin, S. O. Grim and W. E. Swartz, Jr., Inorg. Chem., 1973, 12, 2762.

23. M. Mohai, Surf. Interface Anal., 2008, 40, 710.

24. A. Herrera-Gomez, J. T. Grant, P. J. Cumpson, M. Jenko, F. S. Aguirre-Tostado, C. R. Brundle, T. Conard, G. Conti, C. S. Fadley, J. Fulghum, K. Kobayashi, L. Kover, H. Nohira, R. L. Opila, S. Oswald, R. W. Paynter, R. M. Wallace, W. S. M. Werner and J. Wolstenholme, Surf. Interface Anal., 2009, 41, 840.

25. M. P. Seah, J. H. Qiu, P. J. Cumpson and J. E. Castle, Surf. Interface Anal., 1994, 21, 336.

26. R. Brundle, G. Contia, P. Mack and J. F. Watts, J. Electron Spectros. Related Phenom., 2010, 178-179, 433.

27. J. F. Watts and J. Wolstenholme, An introduction to surface analysis by XPS and AES, John Wiley \& Sons, 2003.

28. J. B. Parise, K. Leinenweber, D. J. Weidner, K. Tan and R. B. Von Dreele, American Mineralogist, 1994, 79, 193.

29. S. Krawczyk and M. Gdaniec, Acta Cryst., 2005, E61, 2967.

30. L. P. Kazansky, I. A. Selyaninov and Yu. I. Kuznetsov, Appl. Surf. Sci., 2012, 259, 385. 